\title{
Effect of Temperature on Precipitation Rate of Calcium Carbonate Produced through Microbial Metabolic Process of Bio Materials
}

\author{
Putri, P.Y.1,2,", Kawaai, K. ${ }^{1}$, Ujike, I. ${ }^{1}$, and Yamamoto, S. ${ }^{1}$
}

\begin{abstract}
Concrete is the most widely used construction material in civil engineering. But plain concrete is a brittle material and has little resistance to cracking. The cracking in concrete promotes deterioration such as the corrosion of reinforcing rebar, therefore, repair in filling the crack is often carried out. Recently, repair methods using bio-based materials associated with microbial metabolic processes leading to precipitation of calcium carbonate have been intensively studied. In this study, influencing factors on the precipitation rate depending on the constituents of bio-based material comprising yeast, glucose and calcium acetate mixed in tris buffer solution was examined for improving the rate of initial reactions. In addition, effect of temperature change on the amount of calcium carbonate precipitation was also investigated. The precipitates were identified by X-ray diffraction. It was shown that the increase of temperature lead to a change on calcium carbonate precipitation and caused the $\mathrm{pH}$ decrease under 7.0.
\end{abstract}

Keywords: Bio-based repair materials; yeast; calcium carbonate precipitation; temperature.

\section{Introduction}

Concrete structures have been commonly used in infrastructure facilities. Concrete has a great variety of applications because it not only meets structural demands but also lends itself readily to architectural treatment. Although quality control of concrete used in these structures is strictly required, initial defects are likely to occur owing to structural constraints and poor workmanship, for example, construction-joint or gap especially at joints between structural members used in bridge structures. When it rains, it may cause leakage from the gap leading to a decrease in serviceability and should be aesthetically unacceptable.

Difficulties associated with repair techniques for such defects are that conventional repair materials are less effective in sealing the gap formed spatially distributed in large areas, especially deeper zones in concrete structures. In organic materials, e.g. cementbased grout materials with higher viscosity, are less practical in repairing deeper zones of cracks or gaps in large areas. In addition, they may cause adverse effect on the natural environment if they flow out through the gaps or cracks which are not completely repaired.

\footnotetext{
${ }^{1}$ Graduate School of Science and Engineering, Ehime University, Matsuyama 790-8577, JAPAN.

2 Department of Civil Engineering, Universitas Negeri Padang, Padang 25000, INDONESIA.

*Corresponding author; e-mail: prima.yane.putri@gmail.com
}

Note: Discussion is expected before November, $1^{\text {st }} 2016$, and will be published in the "Civil Engineering Dimension" volume 19, number 1, March 2017.

Received 14 August 2016; revised 21 August 2016; accepted 26 August 2016.
Therefore, it is advantageous if the materials are not based on such materials, however, it should have similar materials properties of concrete.

Recently, liquid-based repair techniques in the field of self-healing through the use of microbial induced precipitation (MIP) have been intensively investigated [1-7]. The mixtures are comprised of microorganism, organic carbon source and calcium source which is readily available in concrete. When dry yeast is selected as the microorganism, carbon dioxide produced through the microbial metabolic processes consumes organic carbon source, such as glucose, provides carbonate ions. The carbonate ions lead to react with calcium ions present in the mixture, leading to the precipitation of calcium carbonate depending on the $\mathrm{pH}$ levels in the alkali environment. The $\mathrm{CaCO}_{3}$ precipitates according to the following reactions:

$$
\begin{aligned}
& \mathrm{C}_{6} \mathrm{H}_{12} \mathrm{O}_{6} \rightarrow 2 \mathrm{CO}_{2}+2 \mathrm{C}_{2} \mathrm{H}_{5} \mathrm{OH} \\
& \mathrm{CO}_{2}+\mathrm{H}_{2} \mathrm{O} \rightarrow \mathrm{CO}_{3}^{2-}+2 \mathrm{H}^{+} \\
& \mathrm{Ca}^{2+}+\mathrm{CO}_{3}^{2-} \rightarrow \mathrm{CaCO}_{3} \downarrow
\end{aligned}
$$

It should be noted that the material produced through the reactions is not harmful to concrete materials because the precipitates are mainly comprised of calcium carbonate which is one of the reaction products formed by carbonation of hydration products. Besides the material properties, the mixture is a less viscous material compared to conventional materials. This may overcome shortcomings associated with the conventional repair materials as mentioned previously. Thus, it would be beneficial if the mixtures penetrate into deeper zones of gaps 
formed between concrete members and could effectively improve the water tightness of concrete with defects. However, the precipitation rate especially at early stages depending on the concentrations and initial $\mathrm{pH}$ levels.

Many studies have been carried out to investigate the effect of temperature on the $\mathrm{CaCO}_{3}$ precipitation and its incorporation into the calcite crystal lattice. Karoui et al. [8] studied the effect of magnesium and sulphate ions on the kinetics precipitation and morphology of aragonite at fixed temperature of $60^{\circ} \mathrm{C}$. It was shown that the magnesium ions were inserted in the aragonite crystal structure by substituting calcium ions. This substitution depends on the $\mathrm{Mg}^{2+}, \mathrm{Ca}^{2+}$ and $\mathrm{So}_{4}^{2-}$ ions concentrations. Weiss et al. [9] investigated the effect of synthesis temperature on the abundance of vaterite, aragonite, and calcite, thus delineating regions that are favorable for the formation of these different calcium carbonate polymorphs at temperatures ranging from 25 to $80^{\circ} \mathrm{C}$. Therefore, in this research, the effects of temperature change were examined to enhance the precipitation rate of the calcium carbonate in bio based repair materials comprising yeast, glucose and calcium acetate. In order to evaluate the effect of temperature, X-ray powder diffraction (XRD) analysis was conducted. Finally, the relation between XRD analysis and polymorph of calcium carbonate precipitated was examined.

\section{Methodology}

\section{Selection of Basic Constituents of Mixtures}

Along this study, calcium carbonate precipitation was promoted by microbial metabolic process of biomaterials mixtures as shown in Figure 1. In addition to the reaction, it is essential to control the $\mathrm{pH}$ levels in mixtures to facilitate the precipitation of calcium carbonate. Tris (tris hydroxymethyl aminomethane) buffer solution with an alkali buffering function was used in this study. The initial $\mathrm{pH}$ in the Tris buffer solution was adjusted to 8.0 using hydrochloric acid. The use of hydrochloric acid should be minimized in adjusting $\mathrm{pH}$ levels for ensuring no adverse effect on the integrity of hardened concrete.

The source of calcium ions used for mixtures was chosen taking into consideration higher solubility and no adverse effect on concrete materials. The material should be also commercially available and cost-effective. Based on the considerations above mentioned, calcium acetate was chosen in this study.

In addition, dry yeast commercially available was used as the microorganism, which is anaerobic and active in the oxygen-free environment. Organic

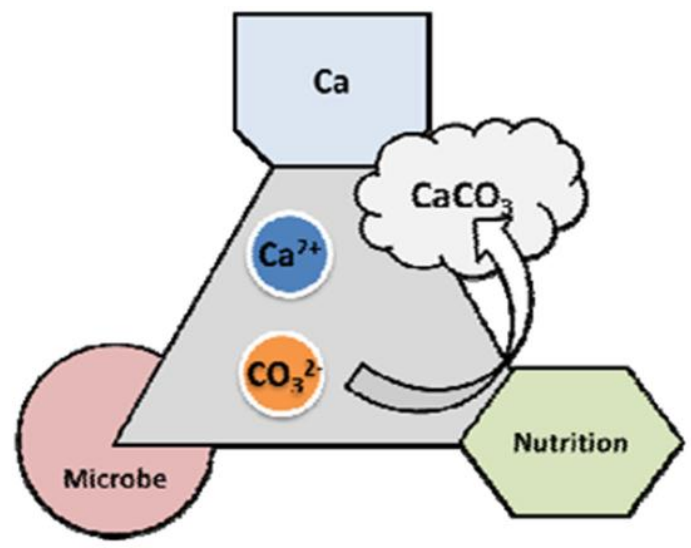

Figure 1. Basic Constituents of Bio-based Repair Material

carbon sources are necessary for the metabolism of the microorganism. Through the anaerobic fermentation, the yeast converts carbohydrates to carbon dioxide and alcohols in the presence of glucose $\left(\mathrm{C}_{6} \mathrm{H}_{12} \mathrm{O}_{6}\right)$ which was selected as an organic carbon source.

It is known that highly alkaline environment, in which pore solution in concrete exhibits, is a severe condition for the yeast. It is crucial for the microorganism to exist in the mixtures with relatively lower $\mathrm{pH}$, which is adjusted as low as possible initially. According to previous research, it has been reported that the precipitation of calcium carbonate was likely to be smaller when $\mathrm{pH}$ decreased less than 7.5 [4]. In order to maintain the appropriate $\mathrm{pH}$ levels in mixtures tested, the $\mathrm{pH}$ was initially adjusted as 8.0 in room conditions controlled at $20^{\circ} \mathrm{C}$. With the above materials, the mixtures as shown in Table 1 were tested in different temperature conditions controlled at $10^{\circ} \mathrm{C}, 20^{\circ} \mathrm{C}$, and $30^{\circ} \mathrm{C}$.

\section{Testing Procedures}

In order to measure the concentration of calcium ion presence and $\mathrm{pH}$ in mixtures after reaction was started, each mixture was prepared in a test tube. First, each material based on mix proportion specified as shown in Table 1 was prepared and they were mixed with Tris buffer solution in a beaker. The mixture in the beaker was subsequently stirred until each material was dissolved into the solution. And the Tris buffer solution was further added to make solution $30 \mathrm{~mL}$ totally. The test tubes were placed in conditions controlled at $10^{\circ} \mathrm{C}, 20^{\circ} \mathrm{C}$, and $30^{\circ} \mathrm{C}$ for the measurement. The concentration of calcium ions and $\mathrm{pH}$ were measured in filtered mixtures using commercially available meters (pH/mv meter model SK-620PH and calcium ion electrode model CA-2031). Each test was carried out using two test tubes to confirm the consistency of results obtained. 
Table 1. Mix Proportion of Dry Yeast, Glucose, Calcium Acetate and Temperature Changing

\begin{tabular}{|c|c|c|c|c|c|c|c|}
\hline \multirow{2}{*}{ Cases } & \multirow{2}{*}{ Dry yeast } & \multirow{2}{*}{$\begin{array}{c}\text { Glucose } \\
(\mathrm{mol} / \mathrm{L})\end{array}$} & \multirow{2}{*}{$\begin{array}{c}\text { Calcium acetate } \\
(\mathrm{mol} / \mathrm{L})\end{array}$} & \multicolumn{2}{|c|}{ Tris buffer solution } & \multirow{2}{*}{ Temperature } & \multirow{2}{*}{$\begin{array}{l}\text { Elapsed time } \\
\text { (hours) }\end{array}$} \\
\hline & & & & $\mathrm{pH}$ & $(\mathrm{Mol} / \mathrm{L})$ & & \\
\hline A1 & \multirow{6}{*}{9.0} & \multirow{6}{*}{0.1} & \multirow{6}{*}{0.05} & \multirow{6}{*}{8.0} & \multirow{6}{*}{0.5} & \multirow{6}{*}{$30^{\circ} \mathrm{C}$} & 12 \\
\hline $\mathrm{A} 2$ & & & & & & & 24 \\
\hline A3 & & & & & & & 36 \\
\hline $\mathrm{A} 4$ & & & & & & & 48 \\
\hline A5 & & & & & & & 60 \\
\hline A6 & & & & & & & 72 \\
\hline B1 & \multirow{6}{*}{9.0} & \multirow{6}{*}{0.1} & \multirow{6}{*}{0.05} & \multirow{6}{*}{8.0} & \multirow{6}{*}{0.5} & \multirow{6}{*}{$20^{\circ} \mathrm{C}$} & 12 \\
\hline $\mathrm{B} 2$ & & & & & & & 24 \\
\hline B3 & & & & & & & 36 \\
\hline B4 & & & & & & & 48 \\
\hline B5 & & & & & & & 60 \\
\hline B6 & & & & & & & 72 \\
\hline $\mathrm{C} 1$ & \multirow{6}{*}{9.0} & \multirow{6}{*}{0.1} & \multirow{6}{*}{0.05} & \multirow{6}{*}{8.0} & \multirow{6}{*}{0.5} & \multirow{6}{*}{$10^{\circ} \mathrm{C}$} & 12 \\
\hline $\mathrm{C} 2$ & & & & & & & 24 \\
\hline $\mathrm{C} 3$ & & & & & & & 36 \\
\hline $\mathrm{C} 4$ & & & & & & & 48 \\
\hline C5 & & & & & & & 60 \\
\hline $\mathrm{C} 6$ & & & & & & & 72 \\
\hline
\end{tabular}

Based on the results of calcium ions measured, precipitated calcium carbonate was estimated using the following formula:

$$
\mathrm{CaCO}_{\mathrm{a}}=Q(\mathrm{~mol} / \mathrm{L}) \times m(L) \times M\left({ }^{g} /{ }_{\mathrm{mol}}\right) \times \frac{C_{0}-C_{a}}{C_{0}}
$$

Where $\mathrm{CaCO}_{3}$ : the amount of precipitates $(\mathrm{g}), \mathrm{Q}$ : concentration of calcium acetate $(\mathrm{mol} / \mathrm{L}), \mathrm{m}$ : amount of solution (L), M: molar mass of calcium carbonate (100.09), $\mathrm{C}_{0}$ : Initial concentration of calcium ion and $\mathrm{Ca}$ : concentration of calcium ion measured. The precipitates were also tested for X-Ray Diffraction analysis to examine the crystals formed though the microbial metabolic process of bio-based materials in mixtures.

\section{XRD Analysis}

XRD analysis was carried out using the residue left in the test tube after 24 hours, 48 hours and 72 hours. Each sample was crushed and pulverized to an average particle size of less than 10 microns, and then mounted onto an instrument-specific plastic slide plates. Then the mass absorption coefficient of the sample was determined by X-ray transmission. The XRD pattern was obtained by scanning from 5 to 50 degrees, 2 theta using a vertical X-ray diffractometer. The components of the sample were identified by comparing them with database powder diffraction PDF-4/Mineral 2015 established by the International Center for Diffraction Data [10].

\section{Results and Discussion}

\section{Influence of Temperature on Precipitates}

Effect of temperature was examined with respect to precipitation rate up to 72 hours later after mixed. The mixtures cases were as shown in Table 1. Figure 2 shows the precipitates left in tubes after filtering up to 24 hours elapsed time. Visually, calcium carbonate precipitation adhering to test tube increased with increasing temperature. Precipitation of $\mathrm{CaCO}_{3}$ in the case of A mixtures was observed to be greater than precipitation in $\mathrm{B}$ and $\mathrm{C}$ mixtures. Figure 3 shows the precipitates left in tubes after filtering up to 72 hours elapsed time. Precipitation of $\mathrm{CaCO}_{3}$ up to 72 hours elapsed time was observed to be greater than those of 48 hours and 24 hours.

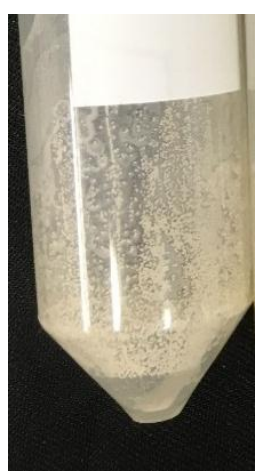

(a)

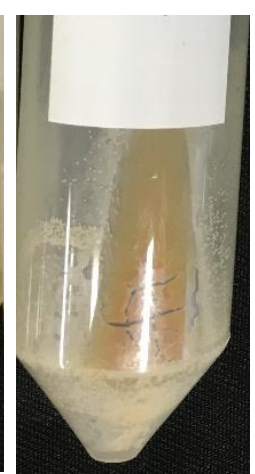

(b)

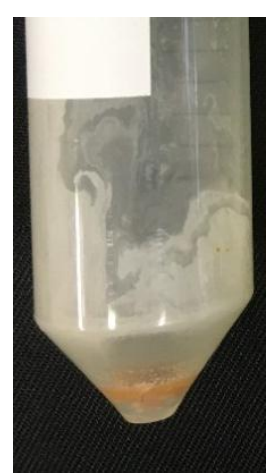

(c)
Figure 2. Precipitates Left After 24 Hours; a) Test Tube in $30^{\circ} \mathrm{C}$, b) Test Tube in $20^{\circ} \mathrm{C}$ and c) Test Tube in $10^{\circ} \mathrm{C}$ 


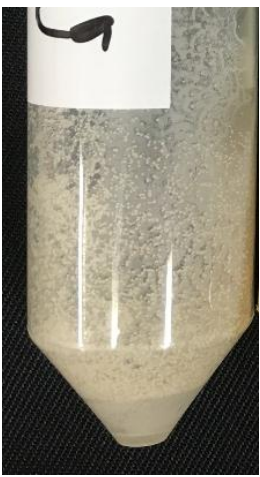

(a)

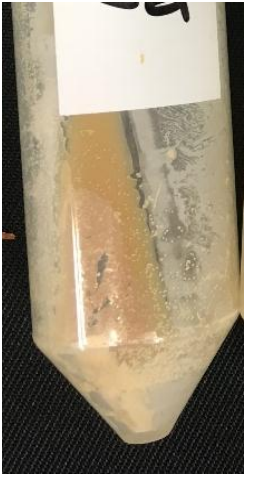

(b)

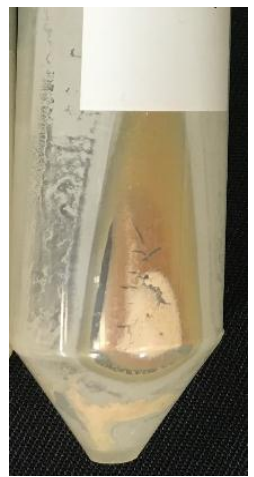

(c)
Figure 3. Precipitates Left After 72 Hours; a) Test Tube in $30^{\circ} \mathrm{C}, \mathrm{b}$ ) Test Tube in $20^{\circ} \mathrm{C}$ and c) Test Tube in $10^{\circ} \mathrm{C}$

Based on the mass of precipitates left in tubes after filtering, precipitation of $\mathrm{CaCO}_{3}$ in the case of $\mathrm{A}$ mixtures up to 24 hours elapsed time was $0.13 \mathrm{~g}$. After 36 hours, it reached $0.14 \mathrm{~g}$ at most until 72 hours elapsed time. In the case of $\mathrm{B}$ mixtures, precipitates left in tubes after filtering up to 24 hours elapsed time was $0.06 \mathrm{~g}$. The precipitation increased to $0.09 \mathrm{~g}$ after 36 hours, $0.10 \mathrm{~g}$ after 48 hours, and gradually increased to 0.13 gram during 60 to 72 hours elapsed time. On the other hand, in the case of $\mathrm{C}$ mixtures, precipitates left in tubes after filtering were less than $0.05 \mathrm{~g}$. Precipitation of $\mathrm{CaCO}_{3}$ up to 24 hours elapsed time was 0.02 g. After 48 hours elapsed time it reached $0.04 \mathrm{~g}$ and it subsequently reached 0.05 gram during 60 to 72 hours elapsed time. Furthermore, in the case of A mixtures, after 24 hours elapsed time the amount of precipitation was constant until 72 hours. In the case of B mixtures, after 24 hours elapsed time, precipitation of $\mathrm{CaCO}_{3}$ increased gradually until 60 hours. After 60 hours, precipitation was constant until 72 hours. Otherwise, in the case of $\mathrm{C}$ mixtures, the amount of precipitation was below $0.05 \mathrm{~g}$ up to 72 hours elapsed time. Figure 4 shows the mass of precipitates left in tubes after filtering for each mixtures up to 72 hours elapsed time.

The results were clearly confirmed by the calcium ion measurement in the mixtures tested. Figure 5 shows the decreasing rate of calcium ion and

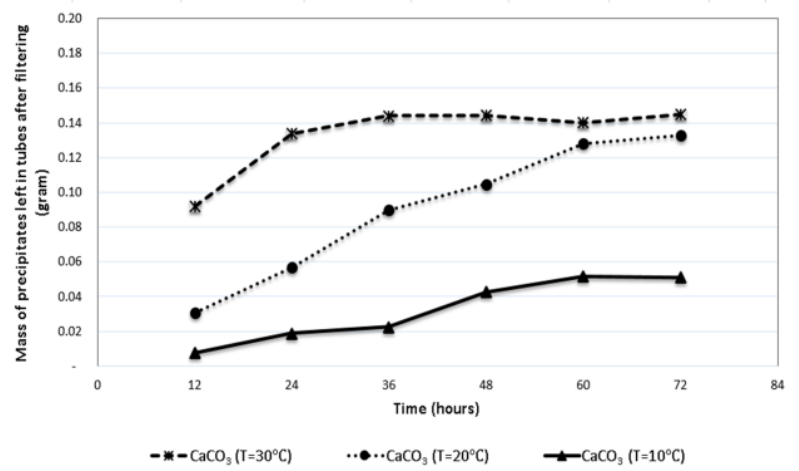

Figure 4. Mass of Precipitates Left in Tubes after Filtering

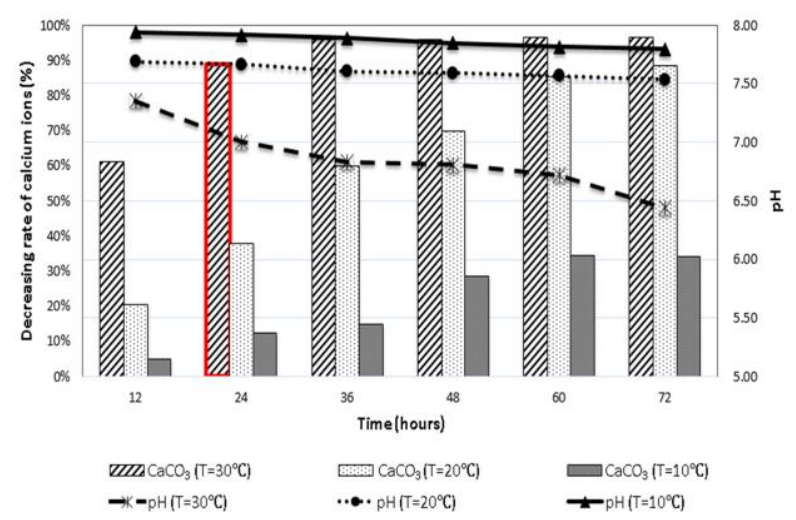

Figure 5. Concentration of Calcium Ions and $\mathrm{pH}$

changes of $\mathrm{pH}$ measured in the mixture tested. As can be seen, the concentration of calcium ion measured in the $\mathrm{C}$ mixtures was decreased by $5 \%$ after 12 hours. The decreasing rate reached about $15 \%$ after 36 hours and reached about $40 \%$ until 72 hours later. On the other hand, in this temperature, the $\mathrm{pH}$ decreased from 8.0 to 7.8 . In the case of $\mathrm{B}$ mixtures, the decrease in the concentration of calcium ion was also notably observed in 12 hours of the monitoring after mixing. The decreasing rate reached about $20 \%$ up to 12 hours of elapsed time and reached almost $90 \%$ after 72 hours. In this condition, the $\mathrm{pH}$ slightly decreased from 7.8 to about 7.5. On the third condition, in the case of A mixtures after 24 hours elapsed time, the concentration of calcium ion was decreased by greater than $90 \%$. On the other hand, the $\mathrm{pH}$ was gradually lowered below 7.0. According to past research, $\quad 80^{\circ} \mathrm{F}-90^{\circ} \mathrm{F} \quad\left(27^{\circ} \mathrm{C}-32^{\circ} \mathrm{C}\right)$ temperature condition are optimum temperature range for yeast to grow and to reproduce at fermentation stage [11]. So, it could increase the amount of calcium carbonate precipitation.

Furthermore, the relation between decreasing rate of precipitation and precipitation rate by filtered paper is shown in Figure 6. Decreasing precipitation rate was measured by using initial concentration of calcium ion $\left(\mathrm{C}_{0}\right)$ and concentration of calcium ion measured (Ca) based on Equation 2. The average difference between the decreasing rate of precipitation measured over precipitation rate calculated by filtered paper was less than $30 \%$. The results were clearly confirmed that decreasing rate of precipitation similar to precipitation rate by measuring filter paper. The maximum precipitation of calcium carbonate was reached at $30^{\circ} \mathrm{C}$ temperature.

\section{Effect of Temperature on Mineral Microstructure}

Calcium carbonate has three anhydrous polymorphs, which are, in order of increasing solubility, calcite 
(rhombohedra), aragonite (orthorhombic) and vaterite (hexagonal). The calcium carbonate polymorph and precipitation rate depend on several parameters; i.e. water composition, temperature, and supersaturation. At ambient temperature, calcite is the most predominant phase [12].

The XRD patterns of the precipitates obtained at three temperature conditions in the presence of

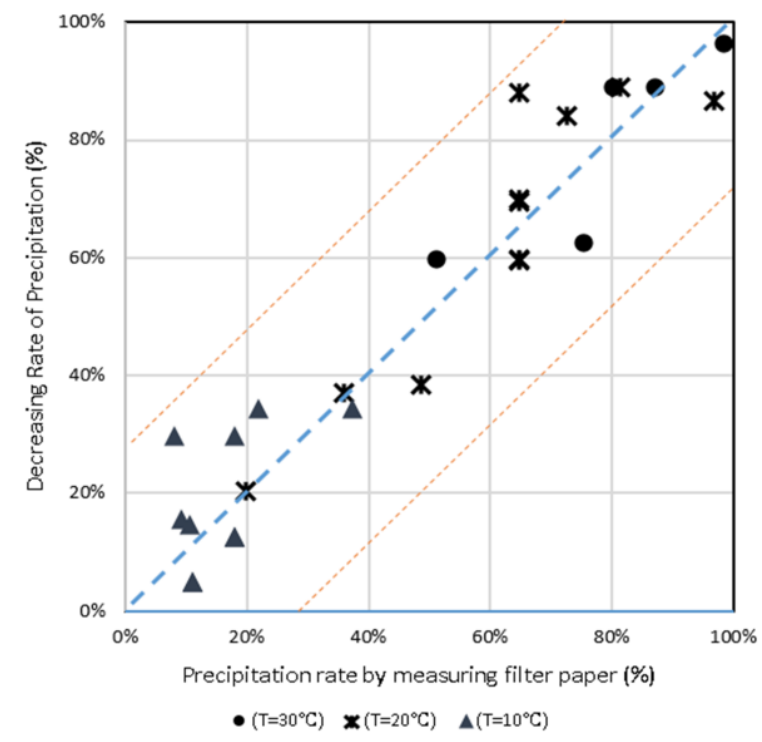

Figure 6. Relation between Decreasing Rate of Precipitation and Precipitation Rate by Filtered Paper

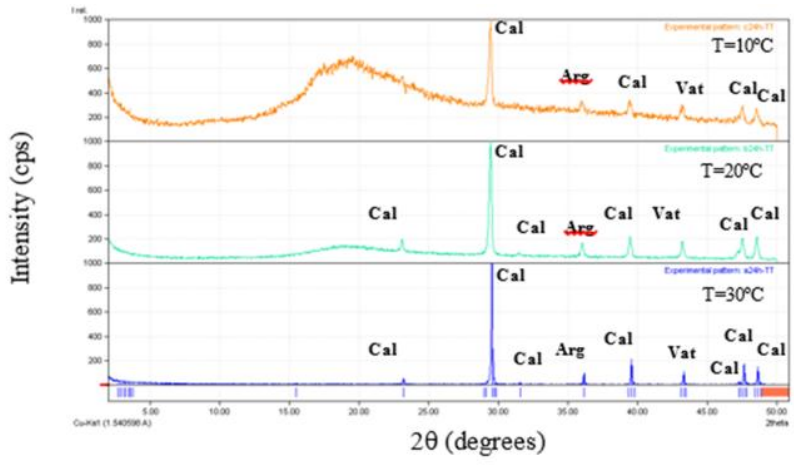

(a)

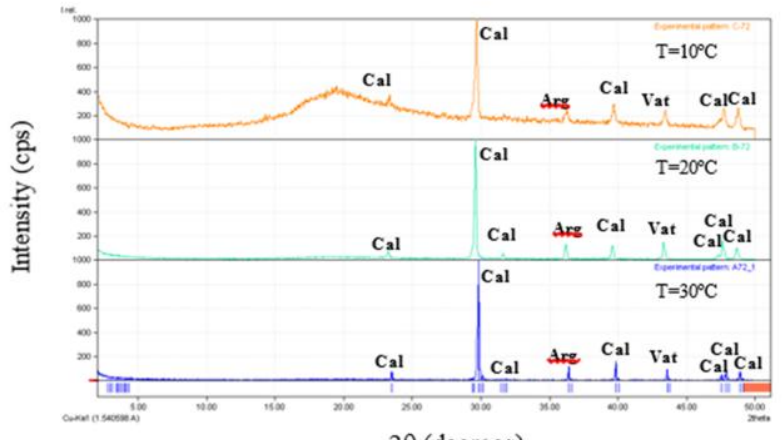

(c)

$2 \theta$ (degrees)
$\mathrm{CaCO}_{3}$ are presented in Figure 7. At $10^{\circ} \mathrm{C}$, the three polymorphs of $\mathrm{CaCO}_{3}$ (aragonite, calcite, and vaterite) coexisted. However, after 24 hours elapsed time there was fluorite in this condition. It is because the growth rate of yeast was significantly reduced at temperatures under $20^{\circ} \mathrm{C}$ [11]. After 48 hours, intensities with respect to calcite increased. Correspondingly, after 72 hours calcite was the dominant polymorph of $\mathrm{CaCO}_{3}$ material as shown in 5 peaks of calcite in XRD pattern.

Similarly, in the $20^{\circ} \mathrm{C}$, there were aragonite, calcite and vaterite polymorph in the calcium carbonate precipitation. After 24 hours elapsed time, there were 6 peaks of calcite, 1 peak of aragonite and 1 peak of vaterite. After 48 hours, the number of calcite polymorph pattern increased to 7 peaks. In the same way, after 72 hours elapsed time showed the same pattern. Otherwise, in the $30^{\circ} \mathrm{C}$ temperature, there were same pattern for 24 hours, 48 hours and 72 hours elapsed time. XRD results showed 7 peaks indicating the presence of calcite from 24 hours elapsed time. It is indicated that calcite should be the dominant or only polymorph of $\mathrm{CaCO}_{3}$ formed by the loss of carbon dioxide if the temperature is the controlling factor. Moreover, when the temperature increased, the intensities of calcite reflections increased and became the major phase. Accordingly, the increase of the temperature promotes the calcite phase. It suggested that the crystals were mainly comprised of calcite.

(b)
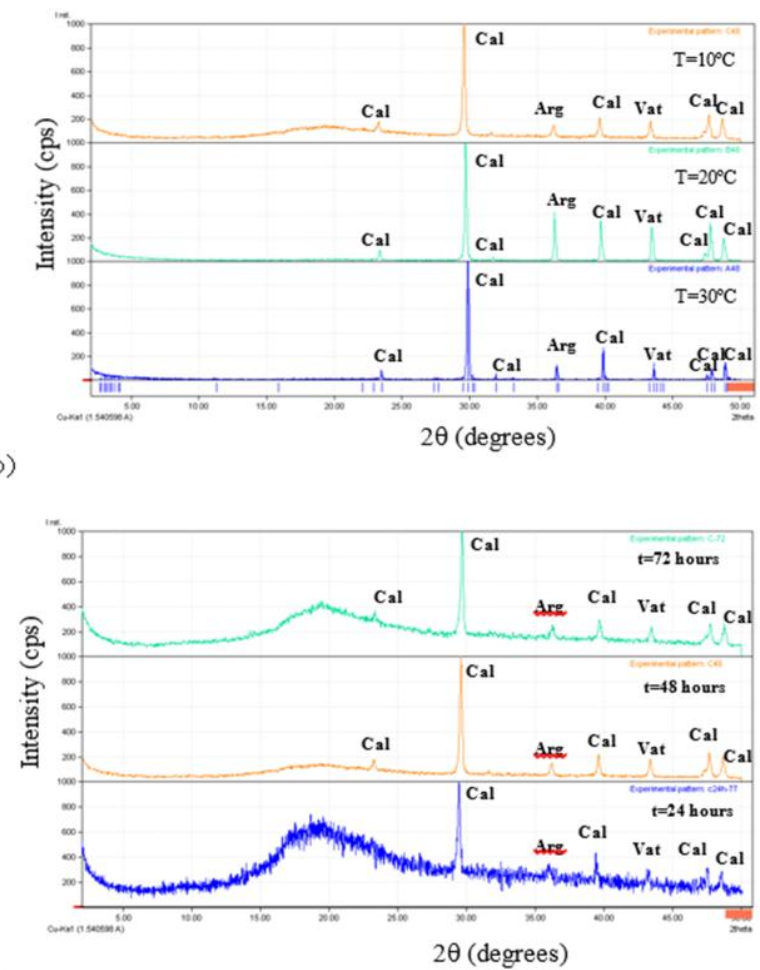

(d)

Figure 7. Superposition of XRD Pattern Obtained at Different Temperature; (a) After 24 Hours Elapsed Time, (b) After 48 Hours Elapsed Time, (c) After 72 Hours Elapsed Time, (d) Samples in $10^{\circ} \mathrm{C}$ After 24, 48 and 72 Hours Elapsed Time 


\section{Conclusion}

The results showed the effects of the temperature changes on the precipitation rate of calcium carbonate. Based on the mass of precipitates left in tubes after filtering, the maximum precipitation of $\mathrm{CaCO}_{3}$ was observed in $30^{\circ} \mathrm{C}$ temperature and the lowest precipitation was in $10^{\circ} \mathrm{C}$ temperature. The results were clearly confirmed by the calcium ion measurement in the mixtures. In $30^{\circ} \mathrm{C}$ temperature, after 24 hours elapsed time, the concentration of calcium ion was decreased by greater than $90 \%$. On the other hand, the $\mathrm{pH}$ was gradually lowered below 7.0. Furthermore, the XRD method also showed effect of temperature changes. When the temperature increased, the intensities of calcite reflections increased and became the major phase. XRD analysis confirmed that calcite should be the dominant polymorph of $\mathrm{CaCO}_{3}$.

\section{Acknowledgements}

The first author achnowledges the scholarship from the Government of Republic of Indonesia through the Directorate General of Human Resource for Science, Technology and Higher Education. This research was supported by Grant-in-Aid for Scientific Research (B): 15H04025. The authors greatly appreciate the financial supports.

\section{References}

1. Kawaai, K., Ujike, I., Putri, P.Y., and Yamamoto, S., Some Considerations on Precipitation Rate of Calcium Carbonate in Bio-based Materials used for Concrete Repair, Concrete Solutions 2016: Proceeding of $6^{\text {th }}$ International Conference on Concrete Repair, Aristotle University of Thessaloniki, Greece, June 20-22, 2016, pp. 580-587.

2. Kawasaki, S., Muaro, A., Hiroyoshi, N., Tsunekawa, M.,. and Kaneko, K., Fundamental Study on Novel Grout Cementing due to Microbial Metabolism, Journal of Japan Society of Engineering Geology, 47(1), 2006, pp. 2-12.
3. Kubo, K., Okazaki, S., and Ujike, I., Development of Microbial Metabolic Processes to Repair Concrete Joint Leakage, Advanced Material Research, 845, 2013, pp. 158-162.

4. Ujike, I., Kubo. F., Kawai, K., and Okazaki, S., Influencing Factors Affecting Microbial Metabolic Processes of Bio Materials used for Leakage Repairs, Concrete Solutions, 2014, pp. 127133.

5. Wiktor, V. and Jonkers, H.M., Quantification of Crack Healing in Novel Bacteria-Based SelfHealing Concrete, Cement \& Concrete Composites, 33(7), 2010, pp. 763-770.

6. Wiktor, V. and Jonkers, H.M., Field Performance of Bacteria-Based Repair System: Pilot Study in a Parking Garage, Case Studies in Construction Materials, 2, 2015, pp. 11-17.

7. Wiktor, V. and Jonkers, H.M., Assessment of The Functionality of Bacteria-based Repair System for Concrete through ESEM Analysis, $15^{\text {th }}$ Euro Seminar of Microscopy Applied to Building Materials, 2015, pp. 165-169.

8. Karoui, H., Korchef, A., Tlili, M. M., Mosrati, H., Gil, O., Mosrati, R., and Ben Amor, M., Effects of $\mathrm{Mg}^{2+}, \mathrm{Ca}^{2+}$, and $\mathrm{SO}_{4}{ }^{2-}$ Ions on Precipitation Kinetics and Microstructure of Aragonite, Annales de Chimie Science des Materiaux, 33(2), 2008, pp. 123-134.

9. Weiss, C.A., Torres-Cancel, K., Moser, R.D., Allison, P.G., Gore, E.R., Chandler, M.Q., and Malone, P.G., Influence of Temperature on Calcium Carbonate Polymorph formed from Ammonium Carbonate and Calcium Acetate, Journal of Nanotechnology and Smart Materials, 1, 2013, pp. 1-6.

10. International Center for Diffraction Data, The Powder Diffraction File (PDF)-4/Minerals, USA, 2015.

11. Gardiner, A. and Wilson, S., Inquisitive Cook: Discover How a Pinch of Curiosity Can Improve Your Cooking, New York: Henry Holt and Co, 1998.

12. Mejri, W., Korchef, A., Tili, M., and Ben Amor, M., Effect of Temperature on Precipitation Kinetics and Microstructure of Calcium Carbonate in The Presence of Magnesium and Sulphate Ions, Desalination and Water Treatment, 52(25-27), 2014, pp. 4863-4870. 